Europe's Journal of Psychology, 7(1), pp. 62-80

www.ejop.org

\title{
An investigation of the effective factors on students' motivational beliefs: The case of Iranian students
}

\author{
Zhaleh Taheri \\ University of Allameh Tabatabaie
}

\begin{abstract}
This study explored the effective factors on students' motivational beliefs (familial, individual, academic and environmental) among Iranian students. The data are derived from a survey using a standard questionnaire with adequate validity and reliability. The participants of the study were selected from high school students in Tehran (total = 518; female $=293(56.6 \%)$ and male $=225(43.4 \%))$ through random sampling and within the age group of 15-18 in May 2010. The data was analyzed with the help of Independent Sample Tests, Pearson Correlations and Multiple Regressions. The results revealed that there is a significant relationship between the above mentioned factors and students' motivational beliefs. The effective factors, in the order of their importance are: environmental factors, individual factors and academic factors. It was observed that familial factors do not have a significant effect on students' motivational beliefs; however this result was different between male and female participants.
\end{abstract}

Keywords: motivational beliefs, automatic strategies, attitude toward school, internal and external control, students.

Motivation is one of the most important elements of our mental life, playing a significant role in learning and achievement. In addition to aptitude, which is one of the important and defining factors in students' learning, there are other effective factors as well. For instance, we can refer to motivational beliefs. Motivation is an internal phenomenon which activates behavior over a time span, directs it and sustains it (Murphy \& Alexander, 2000; Pintrich, 2003; Schunk, 2000; Stipek, 2000). Students who have motivation for learning use higher cognitive processes in learning (Driscoll, 2000; Jetton \& Alexander, 2001; Pintrich, 2003). Generally speaking, there are two types of motivation for learning and development, intrinsic and extrinsic motivations. When people do something to get rewarded or to avoid punishment, 
they are motivated externally. In contrast, motivation is of an intrinsic type when people perform an action following their internal inclination for successfully fulfilling it and ignore the fact that it may be followed by reward or punishment. The positive results of intrinsic motivation outweigh those of extrinsic motivation because intrinsic motivation is a psychological state and occurs when people know themselves to be determined and competent. Both perceptions comprise the concept of control. In the first case, i.e. self-determination, it means having an opportunity for controlling and in the second one, i.e. competence, it means capability of controlling (Moore, 2009; Wright, 2009; Kruse, 2004; Ryan \& Deci, 2002). Motivational beliefs are a series of personal and social criteria to which people refer in order to perform an action (Pintrich, 2000). Their study includes different constructs which belong to different theoretical models such as attribution theory, self-efficiency theory, goal theory and intrinsic motivation theory (Vermer, Boekaerts and Seegers, 2000).

Although there are many effective factors influencing students' motivational beliefs, they can be classified into four general categories: familial, individual, academic and environmental. The decline of learning motivation is a growing problem in today's world. Research findings show that learning motivation decreases during adolescence (Maeher \& Anderman, 1994) and, to be more precise, it reduces during the time between primary school and high school (Slavin, 2001). In determining the reason for the decline of motivation, it is supposed that students after grade school spend less time with their teacher and may have less opportunity to have a close relationship with their teacher; so this aspect can affect their motivational beliefs (Deci \& Ryan, 2000).

\section{Familial Factors}

Concerning familial factors, we can refer to the control by parents, the expectations of parents regarding children's success, the way of raising children, the quality of the parents-child relationship and the socioeconomic situation of the family. Findings of past research reveal that family environment has a significant effect on students' motivational beliefs. In other words it affects their efficiency and also their social goals (Lens, 2005). The authoritative way of training children through kindness and closeness and through clear and obvious rules plays a significant role in students' motivation and learning efficiency. The easy-going or strict parents have a negative impact on their children's learning processes (Ryan, 2001). As a mark of the authoritarian parenting style, parents force children to follow them, apply severe limitations and controls on them, and have slight verbal exchange with each other. In contrast, other parents encourage children to independency and have more verbal exchange with them and support them. What characterizes a neglectful 
parenting style is the fact that parents may not involve themselves in their children's life. Parents may not know for example where their children are or what they are doing. Finally, as an indulgent parenting style, parents interfere more in their children's life and limit them slightly. Such parents let their children do whatever they want (Epstein \& Sanders, 2002).

There has been a lot of research done on the difference between middle class and working class families regarding raising children (Natriello, 2002). Most of the children from low income families are raised in a way that, in contrast to the middle class children, is less in-sync with what is expected from them in school. When middle class children enter school, they are good at following instructions, explaining reasons and understanding them, comprehending difficult language and using it; while working class children have little experience in all these fields (Natriello, 2002). Middle class parents expect their children to be more successful, while working class and lower class parents probably expect them to be more well-behaved (Heyman \& Snook, 2000). The students from families with lower socioeconomic situation are more likely to quit school before entering high school (Ekstrom et al, 1986).

Learning motivation is thus constrained by the quality of the relationship between parents and children. The perceived ability of children and the family environment act as important motivational sources for the person (Ryan \& Patrick, 2001).

\section{Individual Factors}

Individual factors play a defining role in the students' motivational beliefs. Individual factors refer to factors which are about the person him or herself. Considering these factors, we can refer here to learning efficiency, perceived competence, perceived control, attributions, achievement goals and attitudes toward school.

Personal self-efficacy refers to a person's beliefs about his/her effectiveness or ability in a particular field. Investigations show that self-efficacy is important and positively predicts student's self-involvement and self-regulation in a learning session (Zimmerman , 2000). Students who are confident in their learning and writing abilities, are more likely to use successful cognitive and organizational strategies. These strategies involve deep cognitive processing of materials taught during the learning course (Radosevich et al, 2004; Zimmerman, 2000; Pintrich, 2003).

Students' perception of their ability has a significant role for their involvement in academic activities. Therefore, teachers who attempt to improve the learning 
motivation of students should not ignore the role of education in providing an opportunity for understanding the real ability of students (Weiner, 2005). Research shows that there is a positive and significant correlation between perceived ability and learning achievement (Lucangeli \& Scruggs, 2003). Students with higher control perception also have higher intrinsic motivation, try more, mostly use self-regulatory strategies, and generally feel much more control over their life (Perry, 2001). Students' cognitive attitudes toward school also have a significant relationship with learning achievement. Students with high learning achievement become interested in school and have a positive attitude toward school, while a negative attitude might be the result of the weakness in dealing with school (Majoribanks, 1992).

\section{Academic Factors}

The other class of effective factors on students' motivational beliefs is the academic one. In thinking about these factors, we can refer to educational method, learning program or goals and expectations, educational materials, the reward and punishment system set in place, emotional support of students, mutual respect, teacher's enthusiasm and behaviour, teacher and student interactions and assessment method. Most of the families consider the weakness of adolescents' motivational beliefs to be due to education and especially due to teachers. The reason for their belief is the difference between 'love' for education in the first years of entering school and the 'hatred' for the school environment during grade school and high school (Boekaerts, 2002). Providing the reason for reduced educational motivation from primary to high school, Slavin (2001) assumes that because students in grade school and later spend less time with their teacher, and they may have less opportunity to communicate closely with their teacher, this can have a significant influence on their motivational beliefs.

Intrinsic motivation for learning increases through using interesting materials and supplementary materials. For instance, teachers can maintain the interest of the students to learn different disciplines through using overhead projectors, graphs, movies, shows and materials alike. Using a computer can also increase the intrinsic motivation of most of the students (Jetton \& Alexander, 2001).

For the motivation system to be successful, the teacher must provide opportunities not only to reward successes but also to make up for the failures. So, teachers must insist on establishing positive values by providing successful models, improving existing capacities by training for attributing the successes to attempt and failures to lack of attempt, and developing new capacities by training useful skills and approaches to learning and study; they must also guarantee equal and appropriate 
opportunities (such as avoidance of unfair training based on non-logical prejudice) for all the students. Without guiding and suitable calculation, the motivational system cannot properly perform its duties regarding rewarding or making up for the failures (Kermmer, 1990). Motivating adolescents is directly affected by some environmental factors related to school and home, such as communicating with teachers and parents (Lamsen, 1994; quoted by Ryan \& Deci, 2002).

The way in which a teacher assesses his/her students can be effective in reducing their educational failure. Teachers' grades have great motivational value. A teacher can increase learners' motivational level through repeating tests. However, a point that must be mentioned regarding tests and exams is using them as a means for reflection by students about their level of learning rather than as a means of threat and punishment (Woolfolk, 2004). In a study, Keith \& Cool (1992, quoted from Woolfolk, 2004) examined the effects of several important factors such as the ability of learners, training of the teachers, and motivation about learning in more than 25000 students. The most important factor related positively and directly with learning rates was the capability of learners. Then, there were two other important factors, i.e. training the teacher and motivation for learning. Concluding their studies, Keith and Cool wrote "it seems that students who are studying in a school with high quality and high level plans enjoy more incentive. Students who have high educational incentive accept more educational activity, do more homework and consequently achieve more success".

\section{Environmental Factors}

The other type effective factors influencing students' motivational beliefs are environmental factors, among which we can refer to interaction with friends and peers, job opportunities and socio-cultural values. Interaction with peers is considered an important source of support for the growth of adolescents. Peer support is related to the self-esteem of the person (Harter, 1998). An adolescent who does not have a satisfactory relationship with his/her peers is more likely to face problems in the field of learning and compatibility in school. It has been revealed that student's friends can affect whether or not s/he quits school, is absent from school, gets lower grades, and/or has lower motivation and a less positive attitude towards school. On the other hand, friends can help each other in entering college (Ekstrom et al, 1986).

The impact of the socio-cultural factors and conditions on students' educational motivation needs to be considered. The aspiration of having a job with high social 
value in the future increases the self-esteem of the student and leads to higher motivation, feelings of security and a stabilized identity. On the contrary, if society declares that it does not need them and employment is impossible, students will be doubtful and confused and they will suffer from lack of motivation and the fall of selfesteem (Osipow, 1986).

Therefore, as it was mentioned before, based upon theoretical principles and research, the researcher has divided the effective factors on motivational beliefs into four factors, namely familial, individual, academic and environmental.

\section{Method}

\section{Participants}

The participants in this study were 518 students including 293 females (56.6 \%) and 225 males (43.4\%) aged $15-18$ with the mean age of 16.16 years old and standard deviation of 0.93. 41.1 percent of the students were in the first grade in high school, 29.2 percent in the second grade and 29.7 percent in the third grade.

\section{Materials}

Considering the method, the researcher first provided a questionnaire to analyze the views of experts (specialists in the fields of psychology, educational psychology and study planning). Then, after a poll of experts, the effective factors influencing the improvement of students' motivational beliefs were revealed. In the next step, standard questionnaires focused on these factors (grouped in the four categories described above) were designed and administered to students in May of 2010.

The materials used in this research involve the following:

1- Motivated Strategies for Learning Questionnaire (MSLQ),

2- The School Attitude Assessment Survey_Revised (SAAS_R),

3- Rotter's Internal - External Control Scale,

4- Researcher designed questionnaire for assessing academic factors,

5- Researcher designed questionnaire for assessing social values and culture

6- Family socio-economic status questionnaire.

MSLQ scales tap into three broad areas: (1) value (intrinsic and extrinsic goal orientation, task value, e.g. "In a class like this, I prefer course material that really challenges me so I can learn new things"), (2) expectancy (control beliefs about learning, self-efficacy, e.g. "I'm certain I can understand the most difficult material"); 
and (3) affect (test anxiety). The learning strategies section is comprised of nine scales which can be distinguished as cognitive, metacognitive, and resource management strategies. The cognitive strategies scales include (a) rehearsal, (b) elaboration (e.g. "I try to relate ideas in this subject to those in other courses whenever possible"), (c) organization, and (d) critical thinking. Metacognitive strategies are assessed by one large scale that includes planning, monitoring, and regulating strategies. Resource management strategies include (a) managing time and study environment; (b) effort management, (c) peer learning, and (d) help seeking. Scale reliabilities are robust, and confirmatory factor analyses demonstrated good factor structure. In addition, the instrument showed reasonable predictive validity to the actual course performance of students. The reliability of each area of this scale for an Iranian student population was as follows: value (0.72), expectancy (0.73), affect (0.72), cognitive strategies (0.71), and metacognitive strategies (0.69).

The SAAS-R measures five factors: academic self-perceptions, attitude toward teachers, attitude toward school, goal valuation, and motivation/self-regulation. McCoach and Siegle (2003) reported that the SAAS-R was developed to explore the relationship between these five factors and scholastic underachievement in academically able students. The SAAS-R employed a Likert type agreement scale ranging from 1 to 7 , where 1 represented "strongly disagree" and 7 represented "strongly agree". It contains 43 items. A confirmatory factor analysis of the SAAS-R indicated that the data provided a reasonable fit to a model with five correlated factors (McCoach \& Siegle, 2003). Each of the five factors in the sample has reliability estimates ranging from 0.89 to 0.95 (McCoach \& Siegle, 2003). The reliability of each of the five factors for the Iranian population was as follows: academic selfperceptions (0.72), attitude toward teachers (0.87), attitude toward school (0.90), goal valuation (0.77), and motivation/self-regulation (0.86). The reliability of the full scale was 0.87 .

Rotter's Internal-External Control Scale has a forced-choice format with an internal belief pitted against an external belief. For example, on one item participants must choose whether people's misfortunes are due to their own mistakes (internal) or due to bad luck (external). This scale has 29 items and the items on the scale are classifiable into six subcategories on the basis of the types of needs that are portrayed and the characteristics of the described goals. The six categories are: academic recognition, social recognition, love and affection, dominance, sociopolitical beliefs and life philosophy.

For assessing academic factors, the researcher designed a 43-item questionnaire with a 5-point Likert type of answer. This scale measures seven factors: teacher's 
behavior, teacher and student interactions, education method, assessment method, reward and punishment system, learning program or goals and expectations, and educational materials. The reliability of the scale regarding Iranian students was 0.95.

For assessing environmental factors (including social values and culture), the researcher constructed an 11 -item questionnaire and employed a 7-point Likert type agreement scale ranging from 1 to 7 , where 1 represented "strongly disagree" and 7 represented "strongly agree". For example, "in our culture, joblessness and laziness are considered inappropriate". The reliability (alpha) of this scale in the case of Iranian students was 0.69 .

The Family socio-economic status questionnaire asked for information about the education and profession of parents, housing, car ownership and facilities which parents can provide for their children. The reliability for an Iranian sample was 0.86 .

In conclusion, the variables of the study and their corresponding measurement were:

Variables

Motivational Beliefs

Familial Factors

Individual Factors

Academic Factors

Environmental Factors
Instruments

Motivated Strategies for Learning Questionnaire (MSLQ)

Family socio-economic status questionnaire

The School Attitude Assessment Survey _ Revised (SAAS_R)

Rotter's Internal_External control scale

Researcher designed questionnaire

Researcher designed questionnaire

It needs to be mentioned that the validity and reliability of the questionnaires were analyzed and confirmed in Iran and foreign countries (Pintrich, Mc keachie, Smith \& Garcia, 1993). After data collection, the results were analyzed using the SPSS software. Descriptive statistics (frequency, percentage, mean and standard deviation) were used for the description of data, and inferential statistics (independent Sample Test, Pearson Correlation and Multiple Regression) were used for analysis. 
Results

The statistical analysis shows that the mean of female students' motivational beliefs is higher than the mean of male students' motivational beliefs and the difference between male and female students is statistically significant ( $p<0.05)$. To put it in another words, girls have higher motivational beliefs in comparison to boys (Table 1).

The average of the scores of students' motivational beliefs in the first, second and third grades were similar and the difference among them was not statistically significant ( $p>0.05)$ (Table 2).

Table 1: The comparison of the students' motivational beliefs with regard to sex

$\begin{array}{lllllll}\text { Sex } & N & M & \text { SD } & \dagger & \text { d.f } & \text { P value } \\ \text { female } & 282 & 158.34 & 21.47 & 2.0999 & 497 & 0.036 \\ \text { male } & 217 & 154.07 & 23.77 & & & \end{array}$

Table 2: The comparison of the students' motivational beliefs with regard to grade

$\begin{array}{lllllll}\text { Grade } & N & M & \text { SD } & F & \text { d.f } & \text { P valu } \\ \text { First } & 201 & 157.25 & 23.781 & & & \\ \text { Second } & 148 & 153.63 & 22.558 & & & \\ \text { Third } & 150 & 158.27 & 20.724 & & & \\ \text { Total } & 499 & 156.48 & 22.571 & & & \end{array}$

Results show there is a significant relationship between students' motivational beliefs and academic, individual (attitude toward school and Internal control) and environmental factors (culture and social values) $(\mathrm{P}<0.01$ ) and their relationship with familial factors (socio-economic situation) was not significant ( $P>0.05$ ) (Table 3). According to the statistics, there is a significant relationship between male students' motivational beliefs and academic, individual (attitude toward school and Internal control), and environmental factors (culture and social values) ( $\mathrm{P}<0.01$ ) and also with familial factors (socio-economic situation) ( $P<0.05)$ (Table 4). 
Table 3: Correlation matrix of students' motivational beliefs with academic, individual, environmental and familial factors

\begin{tabular}{llllll} 
Variables & $\begin{array}{l}\text { Motivational } \\
\text { Beliefs }\end{array}$ & $\begin{array}{l}\text { Academic } \\
\text { Factors }\end{array}$ & Factors & Factors & Factors \\
Motivational & 1 & & & & \\
Ácademic & $0.248\left(^{* *}\right)$ & 1 & & \\
- Individual Factors & $0.426\left(^{* *}\right)$ & $0.266\left(^{* *}\right)$ & 1 & \\
Environmental & $0.440\left(^{* *}\right)$ & $0.160\left(^{* *}\right)$ & $0.526\left(^{* *}\right)$ & 1 & \\
- Familial Factors & -0.002 & 0.072 & $\left.-0.106^{*}\right)$ & -0.065 & 1 \\
\hline
\end{tabular}

$\left(^{*}\right)$ significance in the level of 0.05 and (**) significance in the level of 0.01

Table 4: Correlation matrix of students' motivational beliefs (male) with academic, individual, environmental and familial factors

\begin{tabular}{llllll} 
Variables & $\begin{array}{l}\text { Motivational } \\
\text { Beliefs }\end{array}$ & $\begin{array}{l}\text { Academi } \\
\text { c Factors }\end{array}$ & $\begin{array}{l}\text { Individual } \\
\text { Factors }\end{array}$ & $\begin{array}{l}\text { Environmenta } \\
\text { I Factors }\end{array}$ & $\begin{array}{l}\text { Familial } \\
\text { Factors }\end{array}$ \\
Ácadivational & 1 & & & & \\
- individual Factors & $0.425\left(^{* *}\right)$ & $0.331\left(^{* *}\right)$ & 1 & & \\
Environmental & $0.447\left(^{* *}\right)$ & $0.167\left(^{*}\right)$ & $0.631\left(^{* *}\right)$ & 1 & 1 \\
- Familial Factors & $-0.157\left(^{*}\right)$ & -0.129 & $-0.242\left(^{* *}\right)$ & $-0.218\left(^{* *}\right)$ & 1 \\
\hline
\end{tabular}

$\left(^{*}\right)$ significance in the level of 0.05 and $\left({ }^{* *}\right)$ significance in the level of 0.01

The relationship between female students' motivational beliefs with academic, individual (attitude toward school and Internal control), and environmental factors (culture and social values) is significant at the level of $\mathrm{P}<0.01$ and is not significant in the case of familial factors (socio-economic status) ( $P>0.05$ ) (see Table 5). 
Table 5: Correlation matrix of students' motivational beliefs (female) with academic, individual, environmental and familial factors

\begin{tabular}{|c|c|c|c|c|c|}
\hline Variables & $\begin{array}{l}\text { Motivational } \\
\text { Beliefs }\end{array}$ & $\begin{array}{l}\text { Academic } \\
\text { Factors }\end{array}$ & $\begin{array}{l}\text { Individual } \\
\text { Factors }\end{array}$ & $\begin{array}{l}\text { Environmental } \\
\text { Factors }\end{array}$ & $\begin{array}{l}\text { Familial } \\
\text { Factors }\end{array}$ \\
\hline Motivational & 1 & & & & \\
\hline Ácádemic & $0.242\left(^{* *}\right)$ & 1 & & & \\
\hline individual Factors & $0.432\left(^{* *}\right)$ & $0.252\left(^{* *}\right)$ & 1 & & \\
\hline Environmental & $0.427\left(^{* *}\right)$ & 0.099 & $0.414\left(^{* *}\right)$ & 1 & \\
\hline Familial Factors & 0.097 & -0.026 & 0.039 & 0.025 & 1 \\
\hline
\end{tabular}

$\left(^{*}\right)$ significance in the level of 0.05 and $(* *)$ significance in the level of 0.01

The results of the Linear and Simultaneous regression revealed that the effect of academic, individual (attitude toward school), and environmental (culture and social values) on students' motivational beliefs is statistically significant $(P<0.01)$, while other factors (age, grade, external control and socio-economic status of the family) are not statistically significant. Also, the effective factors influencing students' motivational beliefs in the order of importance are as following: environmental factors, individual factors, academic factors, educational grade, familial factors and age (Table 6).

Table 6: The impact of factors on students' motivational beliefs

\begin{tabular}{ccccc} 
Entered Variables & $b$ & Beta & $\dagger$ & $P_{\text {_value }}$ \\
Age & -0.527 & -0.022 & -0.314 & 0.754 \\
Educational Grade & 1.746 & 0.064 & 0.911 & 0.363 \\
\hline Academic Factors & 0.95 & 0.128 & 3.010 & 0.003 \\
Individual Factors & 0.236 & 0.222 & 4.629 & 0.000 \\
\hline Environmental Fact. & 0.917 & 0.336 & 6.997 & 0.000 \\
Familial Factors & 0.168 & 0.028 & 0.668 & 0.505
\end{tabular}

Note: The three sections in the table show the steps of entering variables into the analysis

\section{Discussion}

The results of the survey administered to students revealed that the most important effective factors influencing their motivational beliefs can be put in the following order: environmental factors (culture and social values), individual factors (attitude toward school), academic factors and familial factors (socio-economic status). It 
further revealed that the effective factors influencing male students' motivation are in the following order: environmental factors (culture and social values), individual factors (attitude toward school), academic factors, and familial factors (socioeconomic status). The effective factors influencing female students' motivation factors are in the following order: environmental factors (culture and social values), individual factors (attitude toward school), academic factors, individual factors (attributions) and familial factors (socio-economic status).

It seems the relation between the motivational beliefs of students and academic factors is meaningful because teachers provide an effective training environment and fulfill their training part. They play an important role in creating the incentive in young learners. In the academic environment, pupils develop their cognitive capabilities and competence and attain the knowledge and problem solving skills that are necessary for efficient cooperation in the greater society. In the school and training environment, the knowledge and thinking skills of students are evaluated continuously and compared socially. By achieving the cognitive skills required, pupils attain an increasingly feeling of their mental efficiency. Most social factors apart from official training (such as modeling the cognitive skills of peers, social comparing with the performance of other students, increasing the educational motivation by goals and positive motives and interpretations of coaches for the successes and failures of the student, thus reflecting the desirability and undesirability of their capabilities) will influence the judgments of students about their mental self-efficiency. Therefore, teacher and variables of class environment offer the general framework for the motivational beliefs of students. This conclusion is compatible with studies of Ryan (2001) and Ryan and Deci (2002).

The results of the research for females were the contrasting those for males. In other words, the impact of academic factors on female students' motivational beliefs was statistically significant. This finding is similar to Zimmerman (2000), Ryan \& Deci (2002) and Wigfield (2006)'s research findings. However Winnie-Reid (1996) and Miltiadou (1999)'s research did not show any difference between male and female students regarding motivational beliefs.

Gender differences in the field of education and motivational beliefs are not due to biological factors. But it seems that perception of sexual roles and clichés, incorrect perception of abilities, lack of skill or preparedness, inequality in teaching methods, models and educational opportunities, and lower expectations are among the factors which affect gender differences based on the transference of socio-cultural values through media, governmental organizations, social organizations, home and school organizations (Schunk \& Pajares, 2004). The reason 
one can think of for lack of influence of academic factors on the motivational beliefs of male students seems to be the fact that males, compared with females, may not care much about the behaviors of the teacher, about the training method, evaluation method and interaction and personal communication with their teacher. If a teacher behaves badly with a female student, and punishes her in the classroom, and criticizes her, she will be hurt severely, she might not even have any motivation to come back to school; while such behavior with a male may not be followed by such severe reactions. Female students care much more for having higher grades, for communicating friendly with their teacher as well as for the training method and behavior of teacher than males. Such differences of course are true only on average. Therefore, the above mentioned aspects can be a reason for lack of influence of academic factors on the motivational beliefs of males (Schunk \& Pajares, 2004).

It seems that the reason for the significance of the relationship between students' motivational beliefs and individual factors (attitude toward school and attributions) is due to the defining role of individual factors in students' motivational beliefs. Cognitive theorists believe that the perspectives of the person are the source of his/her motivation; and his/her behavior is made and directed by goals, plans, expectations and attributions about himself/herself. They also believe that behavior is defined by our thought and not simply by past rewards and punishments. Most of current cognitive theories (such as attribution theory, self-efficiency theory, goal theory and intrinsic motivation theory) have a great emphasis on mental structures and organizing experiences. According to this approach, motivation is the result of a person's learned beliefs about individual values, abilities, goals and expectations of the person for acquiring success or failure and positive and negative feelings resulting from self-regulatory processes. The concept of influence of attitude toward school on the motivational beliefs of students, male and female, can be explained such that motivational beliefs of students are influenced by the interaction between many variables. Some are influenced by the student itself, some are related to his/her family, peers, society and culture and the remaining are influenced by school and training system and teacher; so that these factors are not separate from each other, but are interacting. Today, both families and teachers and school attendants emphasize the value of education and this may create a positive motivation for students toward the school because they may attain this belief that they can have a good job and social situation only through higher education (Weiner, 2005). Therefore, the attitude of the students toward school and their attributions can constitute a general framework for their motivational beliefs. This finding is similar to those of Schunk (1984), Bandura (1986), Ames (1990), Wigfield \& Karpathian (1991), 
Majoribanks (1992), Lyon (1993), Weiner (1994), MacCoach (2002), MacCoach \&Siegle (2003) and Pintrich (2003).

As the results of this research revealed, there is no significant relationship between students' motivational beliefs and the socio-economic status of the family. The same results were found for female students, but there was a reverse and significant relationship between males' motivational beliefs and socio-economic status. In other words, those who had a lower socio-economic status of their family had higher motivational beliefs. The reason seems to be this: males from a lower socio economic background have more motivation for studying because they can attain their goals only by education. Males care more for having a good profession and higher social situation than females and believe these purposes are achieved only through education (Sirin, 2003).

The results of the research also revealed that there is a significant relationship between students' motivational beliefs (male and female) and environmental factors (culture and social values). According to Ecological System Theory, proposed by Bronfenbrenner, a person grows in a complex relation system where several levels of environment will influence him/her. The most external surface of Bronfenbrenner's model is the macro system which includes values, rules, customs, and possibilities of a culture. Culture includes norms, customs, behaviors, language and common deductions of a group (King, 2002). A possible reason for this significant relationship is that when students follow the stated principles within their culture and its social values, they receive positive feedback and social rewards and thus are motivated on the part of parents, teachers and school authorities. Being motivated increases the level of attempt made by the individual. More attempt increases positive attributions for more success. All of this optimizes the student's self-esteem and aliments his/her motivational beliefs. The reason for why the relation between motivational beliefs of students and culture and social values is important is that fortunately the view of our community toward education and graduates has been positively changed. As we can see, parents, teachers, training and education as well as public authorities emphasize indirectly the value of education. It is natural that when the convergent messages of parents, teachers and authorities stress the value of education, and there is a sense in which a higher social situation can attain only through education, the student may be motivated and this is what the society wants and the training system needs. The increase in the number of university fields, universities, specialized professions and use of educated individuals for different professions also caused people to believe that education is the most important issue of modern world. 
The present study comes with some limitations that reduce its potential to be generalized. Some of these limitations include running the study in one education and training district of Tehran and including a limited age range (high school students). All this can be expanded in subsequent research. It is also recommended to study the practical ways in which students' motivational beliefs can be enhanced, and this should be studied in the future using experimental designs.

\section{References}

Ames, C. A. (1990). Motivation: What teachers need to know. Teachers College Record, 91, 409- 421.

Bandura, A. (1986). Social foundations of thought and action: A social- cognitive theory. Englewood Cliffs, NJ: Prentice- Hall.

Boekaerts, Monique. (2002). Motivation to learn. Brussel: IAE - IBE UNESCO.

Deci, E. L. , \& Ryan, R. M. (2000). Intrinsic and extrinsic motivation: Classic definitions and new direction. Contemporary Educational Psychology, 25, 54 - 67.

Driscoll, M. P. (2000). Psychology of learning for instruction. (2 $2^{\text {nd }}$ ed.). Boston: Allyn \& Bacon.

Ekstrom, R. B. , Goertz, M. E. , Pollack, J. M. , \& Rock, D. A. (1986). Who drop out of high school and why? Findings from a national study. Teacher College Record , 87, $356-373$.

Epstein, J.L. \&\& Sanders, M.G. (2002). School, family and community partnerships: Your handbook for action (2nd ed.). Thousand Oaks, CA: Corwin.

Harter, S. (1998). The development of self-representations. In W. Damon (Ed.). Handbook of Child Psychology (5th ed. , vol, 3, pp: 553- 618 ). New York: Wiley.

Hayman, I. A. , \& Snook, P. A. (2000). Dangerous schools and what you can do about them. Phi Delta Kappan, 81 (7), 488-50.

Jetton, T. L. , \& Alexander, P. A. (2001). Interest assessment and the content area literacy environment: Challenges for research and practice. Educational Psychology Review, $13(3), 303-318$. 
Kermmer, F. N. (1990). An integrated approach to primary teacher incentives. In Chapman, D., Carrier, C. (Eds.). Improving educational quality: a global perspective (pp. 135-152). Westport, Connecticut: Green Wood Press.

King, E.W. (2002). Ethnicity. In D.L. Levinson, P.W. Cookson, J.R. \& A.R. Sadovnik (Eds.). Education and Sociology: An Encyclopedia (pp: 247- 253). New York: Routledge Falmer.

Kruse, K. (2004). The magic of learner motivation. The ARCS Model . Retrived from http:// www.e - learning guru.com/ articles / art 3-5 htm.

Lens, W. (2005). An integrated model for the study of teacher motivation. Department of Psychology, University of Leuven, Belgium.

Lucangeli, D., \& Scruggs, E. (2003). Advances in learning and behavioral disabilities. Emerald Group Publishing Limited. Vol. 16, pp. 223-230.

Lyon, M. A. (1993). Academic self-concept and its relationship to achievement in a sample of junior high school students. Educational and Psychological Measurement, 53, 201-211.

MacCoach, D. B. (2002). A validation study of the school attitude assessment survey. Measurement and Evaluation in counseling and Development, 35, 66- 77.

MacCoach, D. B. , \& Siegle, D. (2003). The school attitude assessment survey-revised: A new instrument to identify academically able students who underachieve. Educational and Psychological Measurement, 63(3), 414-429.

Maeher, M. L., \& Anderman, E. M. (1994). Motivation and schooling in the middle grades. Review of Educational Research, 64, 287-309.

Majoribanks, K. (1992). The predictive validity of an attitudes toward school scale in relation to children's academic achievement. Educational and Psychological Measurement, $52,945-949$.

Miltiadou, M. (1999). Motivational constructs as predictors of success in the online classroom EMC 703. Arisona State University. Retrieved from http://11 seamonkey. ed. asu.edu/mcisaac/emc703/mavios F.htm.

Moore, K.D. (2009). Effective instructional strategies: from theory to practice. SAGE Publications, Inc. (2nd. ed.). 
Murphy, K. P., \& Alexander, P.A. (2000). A motivated exploration of motivation technology. Contemporary Educational Psychology, 25(1), 3-53 .

Natriello, G. (2002). At risk students. In D.L. Levinson, P.W. Cookson, Jr. \& A. R . Sadovink (Eds.), Education and Sociology: An Encyclopedia (pp: 49 - 54). New York: Routledge Flamer.

Osipow, S. H. (1986). Career issues through the life span. In M. S. Pallak \& R. O. Perloff (Eds.), Psychology and work: Productive, change and employment (pp.141- 168). Washington, DC: American Psychological Association.

Perry, R.P. (2001). Academic control and action control in the achievement of college students: An longitudinal field study. Journal of Educational Psychology, 93 (4).

Pintrich, P.R. (2003). A motivational science perspective on the role of student motivation in learning and teaching contexts. Journal of Educational Psychology, $95(4), 665-686$.

Pintrich, P.R . (2000). Multiple goals, multiple pathways: The role of goal orientation in learning and achievement. Journal of Educational Psychology, 92, 544 - 555.

Pintrich, P.R., Smith, D.A.F., Garcia, T., \& Mckeachie, W.J. (1993). Reliability and predictive validity of the motivated strategy for learning questionnaire (MSLQ). Educational Psychology Measurement, 53, 801- 803.

Radosevich, D., Vaidyanathan, V., \& Yeo, S. (2004). Relating goal orientation to selfregulatory processes: A longitudinal field test. Contemporary Educational Psychology, 29(3), 207- 229.

Ryan, R.M., \& Deci, E.L. (2002). The paradox of achievement: Harder you push, the worse it gets. In J. Aronson (Ed.). Improving academic achievement: Contributions of social psychology (pp. 59 - 85). New York: Academic Press.

Ryan, A.M., \& Patrick, H. (2001). The classroom social environment and changes in adolescents' motivation and engagement during middle school. American Educational Research Journal , 38(2), $437-460$.

Ryan, R.M. (2001). What is being optimized over development? A self-determination theory and basic psychological needs. In Sara Honn Qualls \& Norman Abeles (Ed.) Washington, DC: American Psychological Association. 
Schunk, D. H. (1984). Self-efficacy perspective on achievement behavior. Educational Psychologist, 19, 48- 58.

Schunk, D.H. (2000). Learning theories (3rd. ed.). Upper Saddle River, NJ: Merrill Prentice Hall.

Schunk, D.H. \& Pajares, F. (2004). Self- efficacy in education: Issues and future directions. Paper presented at the annual meeting of the American Educational Research Association, San Diego, CA.

Sirin, S. (2003). Socio economic status and academic achievement: A meta-analytic review of research 1990 - 2000. Paper presented at the annual meeting of the American Educational Research Association, Chicago, IL.

Slavin, R.E. (2001). Putting the school back in school reform. Educational Leadership, 58 (4), 22-27.

Stipek, D. J. (2000). Motivation to learn: From theory to practice. Engelwood Cliffs, NJ , Prentice Hall.

Vermer, H., Boekaets, M. ,\& Seegers, G. (2000). Motivational and gender differences: Sixth grade students, mathematical problem solving behavior. Journal of Educational Psychology, $92(2), 15-30$.

Weiner, B. (1994). Integrating social and personal theories of achievement striving. Review of Educational Research, 64, 557- 573.

Weiner, B. (2005). Motivation from an attributional perspective and the social psychology of perceived competence. In A.J. Elliot \& C.S. Dweck (Eds.). Handbook of Competence and Motivation (pp. 73-8). New York: Guilford.

Wigfield, A. (2006). Development of achievement motivation. Handbook of Child Psychology (6 $6^{\text {th }}$ ed, pp. 933-1002), Vol.3, Social, Emotional, and Personality Development. New York: Wiley.

Wigfield, A. \& Karpathian, M. (1991). Who am I and what can I do? Children selfconcepts and motivation in achievement situation. Educational Psychologist, 26(3-4), 233-261.

Winnie-Reid, E. (1996). Manual for the test of student's perception of readiness. Retrieved from: http://www.arts.auckland.ac.nz/edu/staff/jhattie/winnietest.htm. 
Woolfolk, A. E. (2004). Educational Psychology. (9th Ed.). New York: Pearson.

Wright, T. (2009). How to be a brilliant teacher. London and New York: Routledge. Taylor \& Francis Group.

Zimmerman, B.J. (2000). Self-efficacy: An essential motive to learn. Contemporary Educational Psychology, 25(1), 82-91.

About the author:

Zhaleh Taheri has a PhD in the field of Educational Psychology from the University of Allameh Tabatabaie and her research interests focus on the investigation of the effective factors on Iranian students' motivational beliefs.

Address for correspondence: Zhaleh Taheri, Department of Psychology and Educational Sciences, Pardis Assembly of Allameh Tabatabaie University, Tehran, Iran.

E-mail: zhaleh_taheri@yahoo.com 